\title{
MITIGATION OF HARMONICS IN MULTILEVEL INVERTER USING MSPWM \& SVM TECHNIQUES
}

\author{
Dr.S.Sivakumar ${ }^{1}$, S.Sowmiya ${ }^{2}$ and S.Shangeetha ${ }^{3}$
}

\begin{abstract}
Cascaded Multilevel inverters are getting to be noticeably well known in the field of high power applications. These inverters delivers high power at the output side are favoured for industrial applications. This paper is chiefly focused on Modified Cascaded Multilevel inverter with decreased switches and harmonics. The control signals to the gate are engendered using MSPWM and SVM techniques. The objective of this paper is to diminish switches with increase in multilevel outputs which inherently reduces the cost and harmonics. The inverter is designed and developed in MATLAB ${ }^{\circledR}$ Simulink platform and results are obtained. The examination has been made on Total Harmonic Distortion (THD). The frame work prototype is developed using Power MOSFET Switches and THD is examined using Power Quality Analyser. The results are validated in both Simulation and Hardware.
\end{abstract}

Keywords - Cascaded Multilevel Inverter, Multiple Sinusoidal Pulse Width Modulation (MSPWM) and Space Vector Modulation (SVM), Total Harmonic Distortion (THD)

\section{INTRODUCTION}

Multilevel inverter is utilized ordinarily in the field of Power electronic industries because of its high reliability. Multilevel inverters are exceptionally dependable, exceedingly adaptable, high conversion efficiency, flexible adaptable to improve, low output switching frequency, low cost and the Switching losses is very less in semiconductor switches because of this favourable circumstances the multilevel inverters are well emerged trends in the area of high power applications. When the output level of MLI increases, the switching devices are increased. So the electromagnetic interference conduction noise levels are increased, although the output waveform is similar to sinusoidal and it has less THD.[8]

The different topologies of Multilevel inverter includes Capacitor clamped MLI, Diode clamped MLI, Cascaded MLI [3][4] type. All these topologies are used in different applications. In diode clamped MLI the cost is low but more than three levels the output gets limited. In Capacitor clamped MLI the capacitors have to be pre charged before using it. But Cascaded MLI produce different voltage level and it is easier to analyze. Cascaded multilevel inverters are used in motor drives and in electric vehicle drives. Hence for industrial applications cascaded MLI plays a major role. The seven level output is obtained by the conventional cascaded MLI shown in fig 1 which consists of 12 semiconductor switches. In this proposed cascaded MLI shown in fig 2, 7 switches and 3 diodes are used for seven level output. The multiple sinusoidal and space vector modulation strategies are used in this paper.

\footnotetext{
${ }^{1}$ Department of Electrical and Electronics Engineering Kings College of Engineering, Thanjavur

${ }^{2}$ Department of Electrical and Electronics Engineering Kings College of Engineering, Thanjavur

${ }^{3}$ Department of Computer Science and Engineering, Kings College of Engineering, Thanjavur
} 


\section{CONVENTIONAL CASCADED MULTILEVEL INVERTER}

The conventional cascaded multilevel inverter consists of 2 or more full converter. The full converter has 4 semiconductor switches which are triggered in order to get multilevel output. There are 3 separate DC sources, 12 semiconductor switches in a general 7 level MLI shown in fig 1.

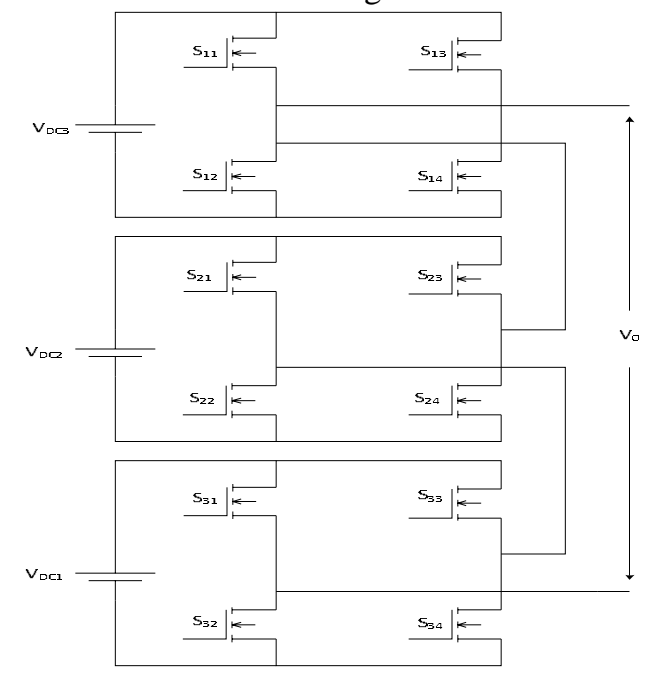

\section{Fig:1 General Cascaded MLI Circuit}

The circuit has $3 \mathrm{dc}$ sources $\mathrm{V}_{\mathrm{DC} 1}, \mathrm{~V}_{\mathrm{DC} 2}, \mathrm{~V}_{\mathrm{DC} 3}$, and 4 switches for each bridge. The first bridge has power semiconductor switches namely $S_{11}, S_{12}, S_{13}, S_{14}$ and for second bridge $S_{21}, S_{22}, S_{23}, S_{24}$ are the power semiconductor switches and for third bridge $S_{31}, S_{32}, S_{33}, S_{34}$ are the power semiconductor switches. The output voltage $\mathrm{V}_{0}$ can be obtained across the first and third bridge. As the switches used in the conventional cascaded multilevel inverter is high, the cost and the switching losses tend to become higher.

\section{MODIFIED CASCADED MULTILEVEL INVERTER}

In a modified cascaded multilevel inverter shown in fig 2, the switching losses becomes less because it has only 7 Power MOSFET switches and 3 power diodes. The intricacy of the circuit is reduced because of less usage of switches. Moreover the modified cascaded MLI was more economical when compared to general cascaded MLI.

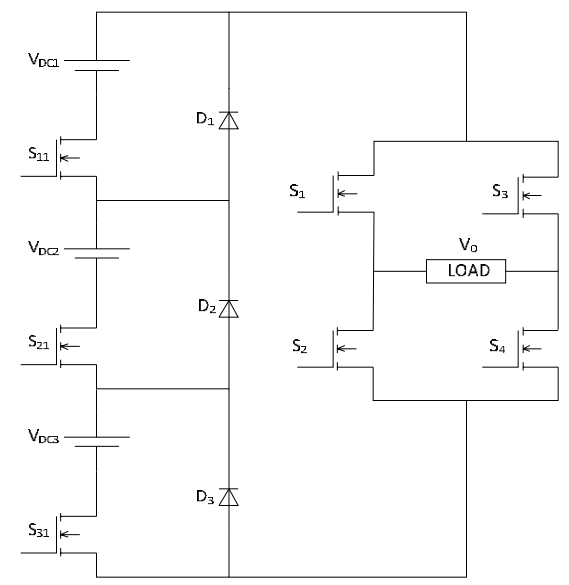

Fig: 2 Modified Cascaded MLI with Reduced Switches 
The circuit has 3 separate DC sources namely $\mathrm{V}_{\mathrm{DC} 1}, \mathrm{~V}_{\mathrm{DC} 2}$ and $\mathrm{V}_{\mathrm{DC} 3}$ and the main power switches are $\mathrm{S}_{11}, \mathrm{~S}_{21}, \mathrm{~S}_{31}$ and for H-bridge $S_{1}, S_{2}, S_{3}$ and $S_{4}$ are used which is for inverter operation.

\begin{tabular}{|c|c|c|c|}
\hline Duration & ON Switches & ON Diodes & $\begin{array}{c}\text { Voltage } \\
\text { Levels }\end{array}$ \\
\hline \multirow{4}{*}{$\begin{array}{c}\text { Positive Half } \\
\text { Cycle }\end{array}$} & - & $\mathrm{D}_{1}, \mathrm{D}_{2}, \mathrm{D}_{3}$ & 0 \\
\cline { 2 - 4 } & $\mathrm{S}_{11}$ & $\mathrm{D}_{2}, \mathrm{D}_{3}$ & $+\mathrm{V}_{\mathrm{DC}}$ \\
\cline { 2 - 4 } & $\mathrm{S}_{11}, \mathrm{~S}_{21}$ & $\mathrm{D}_{3}$ & $+2 \mathrm{~V}_{\mathrm{DC}}$ \\
\cline { 2 - 4 } $\mathrm{S}_{11}, \mathrm{~S}_{21}, \mathrm{~S}_{31}$ & - & $+3 \mathrm{~V}_{\mathrm{DC}}$ \\
\hline \multirow{3}{*}{$\begin{array}{c}\text { Negative } \\
\text { Half Cycle }\end{array}$} & - & $\mathrm{D}_{1}, \mathrm{D}_{2}, \mathrm{D}_{3}$ & 0 \\
\cline { 2 - 4 } & $\mathrm{S}_{11}$ & $\mathrm{D}_{2}, \mathrm{D}_{3}$ & $-\mathrm{V}_{\mathrm{DC}}$ \\
\cline { 2 - 4 } & $\mathrm{S}_{11}, \mathrm{~S}_{21}$ & $\mathrm{D}_{3}$ & $-2 \mathrm{~V}_{\mathrm{DC}}$ \\
\cline { 2 - 4 } & $\mathrm{S}_{11}, \mathrm{~S}_{21}, \mathrm{~S}_{31}$ & - & $-3 \mathrm{~V}_{\mathrm{DC}}$ \\
\hline
\end{tabular}

Table.1: Switching Table for Modified Cascaded Multilevel inverter

\section{OPERATION OF MODIFIED CASCADED MLI}

The conversion unit of the proposed inverter has a power switching device in series with the voltage source and a diode. The number of output levels depends on the number of conversion unit. The output $V_{D C}$ is obtained when triggering $S_{11}$. Similarly $+2 V_{D C}$ is obtained as output voltage as a addition of $V_{D C 1}$ and $V_{D C 2}$ when triggering $S_{11}$ and $\mathrm{S}_{21}$. The output $+3 \mathrm{~V}_{\mathrm{DC}}$ is obtained when all the switches are triggered together.

The unidirectional output levels are converted into bidirectional with the use of $\mathrm{H}$-bridge. In the H-bridge, $\mathrm{S}_{1}$ and $\mathrm{S}_{4}$ are $\mathrm{ON}$ during positive half cycle and $\mathrm{S}_{2}$ and $\mathrm{S}_{3}$ are $\mathrm{ON}$ during negative half cycle. Table 1 shows the operation of switches during positive and negative half cycle. The output waveform of modified cascaded multilevel inverter is shown in fig 6.

The number of output levels $=1+\left(2^{*}\right.$ Number of DC sources $)$

\section{MODULATION STRATEGIES}

I) MSPWM Strategy

The multiple sinusoidal signals are compared with the carrier signal in order to get the desired pulse width [2][5]. The gate pulses are obtained by comparing three sinusoidal waveforms with a single carrier. The output frequency is same as that of the reference waveform.

The frequency modulation and the amplitude modulation are given by

$\mathrm{M}_{\mathrm{f}}=\mathrm{f}_{\mathrm{c}} / \mathrm{f}_{\mathrm{m}}$

$\mathrm{M}_{\mathrm{a}}=2 \mathrm{~A}_{\mathrm{m}} /(\mathrm{N}-1) \mathrm{Ac}$

Where $f_{c}=$ frequency of the carrier signal.

$\mathrm{f}_{\mathrm{m}}=$ frequency of the modulating signal.

$\mathrm{A}_{\mathrm{c}}=$ amplitude of the carrier signal.

$\mathrm{A}_{\mathrm{m}}=$ amplitude of the modulating signal.

$\mathrm{N}=$ number of levels. 


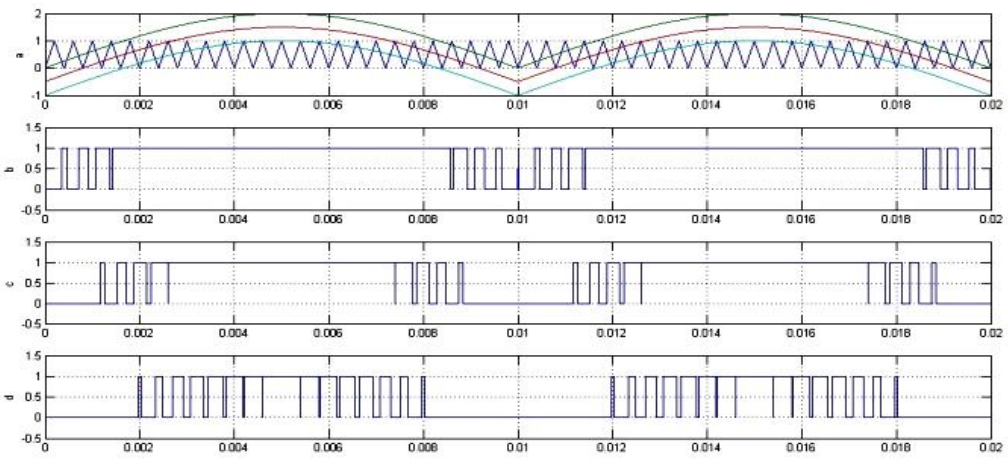

III) SVPWM Strategy

The reference signal is sampled regularly for multiphase ac generation in space vector PWM technique [1][7]. Switching control signals are produced by the SVPWM technique. SVPWM provides low current ripple, low output harmonic distortions when compared with sinusoidal PWM. Also hardware implementation of SVPWM is quite easier.

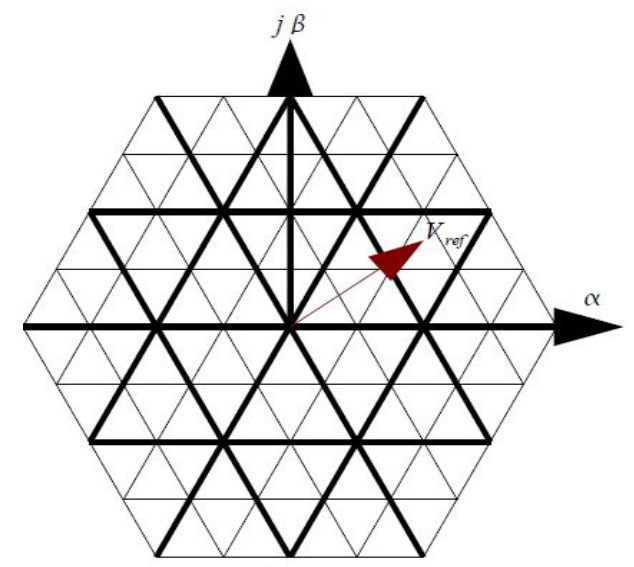

Fig: 3 Space Vector diagram of a multilevel inverter

The $\alpha \beta$-plane represents the reference vector. The three- dimensional plane is transformed into two dimensional plane which consist the vectors of the three phases. The switches being ON or OFF are determined by the location of the reference vector on this $\alpha \beta$-plane [7].

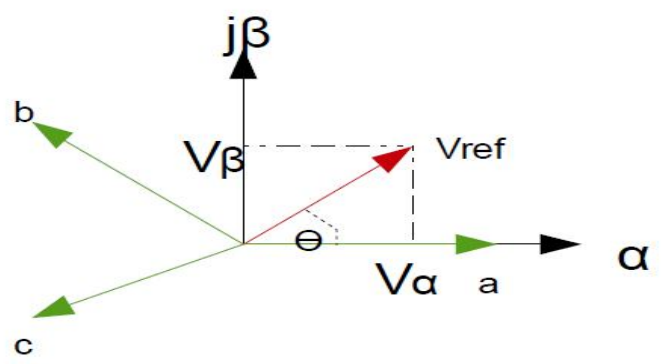


Fig: 4 Reference vector in the two and three dimensional plane

\section{Simulation RESUlts}

Before hardware implementation the circuit is implemented through MATLAB/SIMULINK. . The seven level inverter circuit is simulated in fig. 5 and results of output voltage and THD is shown in fig.6

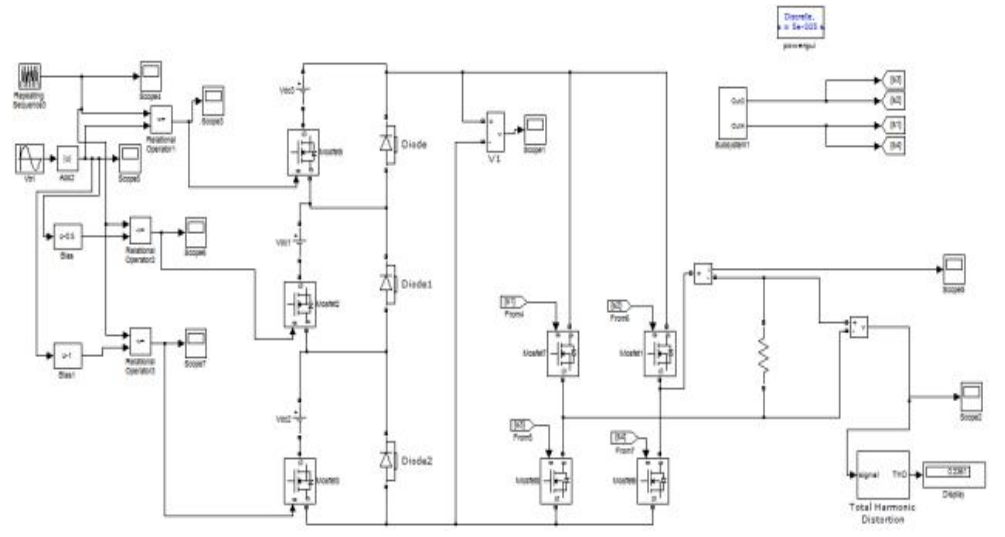

Fig: 7 MATLAB/Simulink Model of Modified Cascaded 7-Level Inverter (MSPWM)

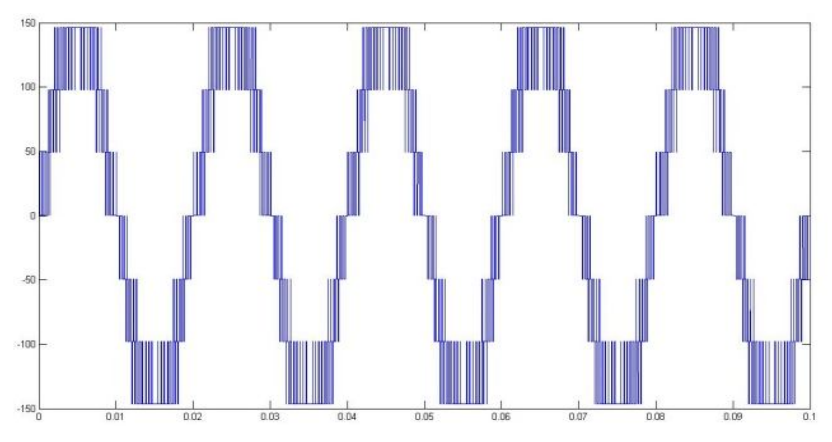

Fig: 8 Seven level output for MSPWM

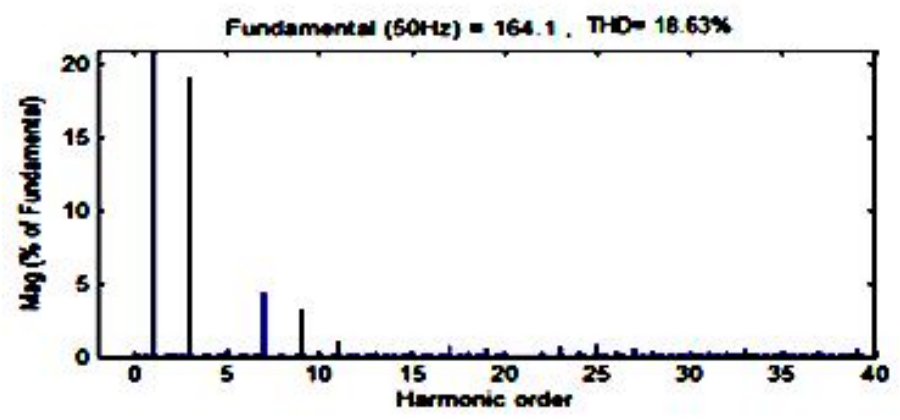

Fig: 9 FFT Analysis for MSPWM 


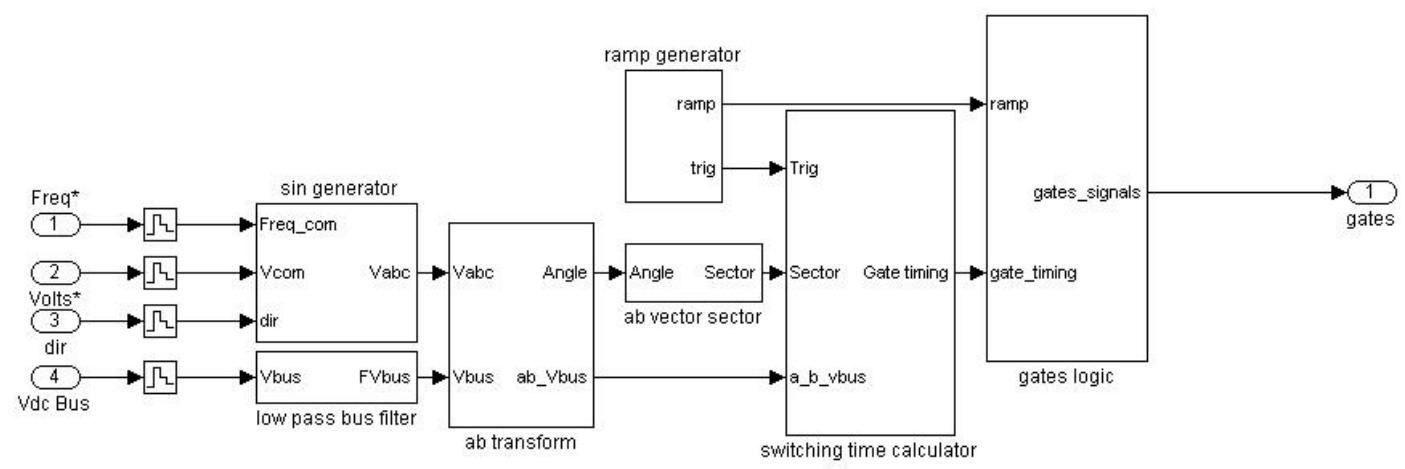

Fig: 10 Gate pulse generation of SVPWM

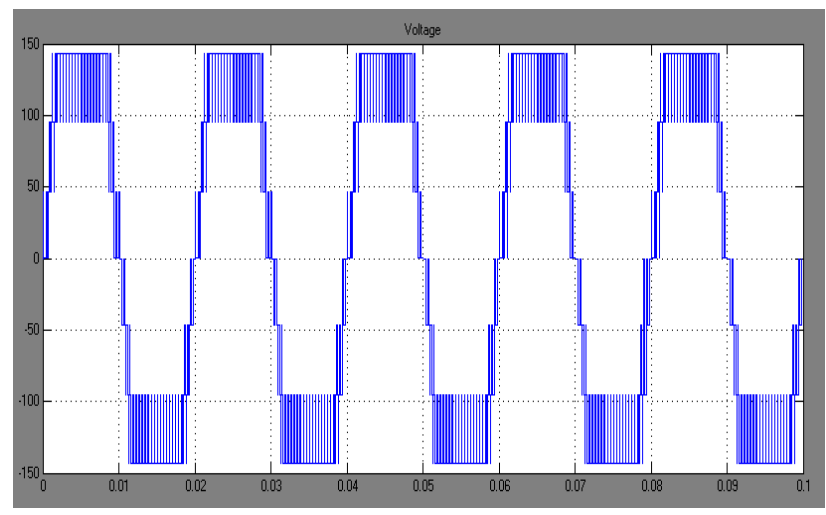

Fig: 11 Seven level output for SVPWM

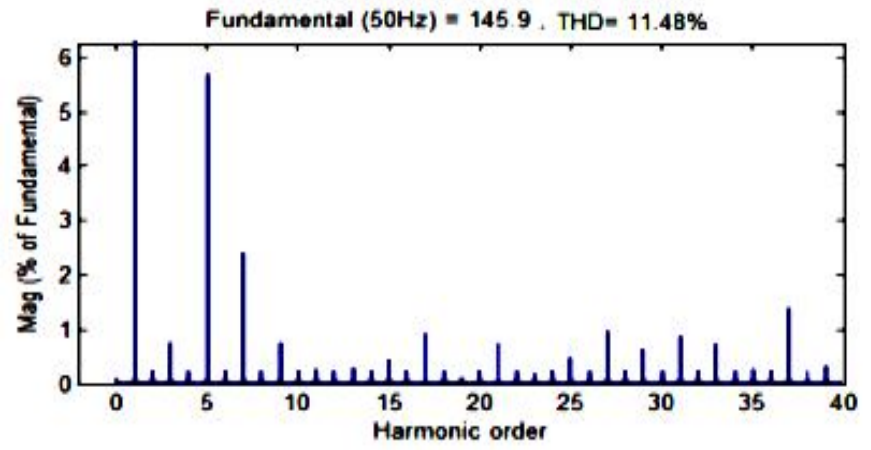

Fig: 12 FFT Analysis for SVPWM

\section{HARDWARE IMPLEMENTATION}

In the hardware implementation of seven level inverter IRF840 MOSFET is used .Simple driver circuits are needed for IRF840 MOSFET. From the microcontroller, gate driver circuit for boosting the pulses is obtained. For the generation of multiple sinusoidal pulses and space vector pulses, programs are written by using PIC16F877A. The power quality analyzer analyzes the THD value and the value is $17.04 \%$ for SVPWM and $25.06 \%$ for MSPWM. 


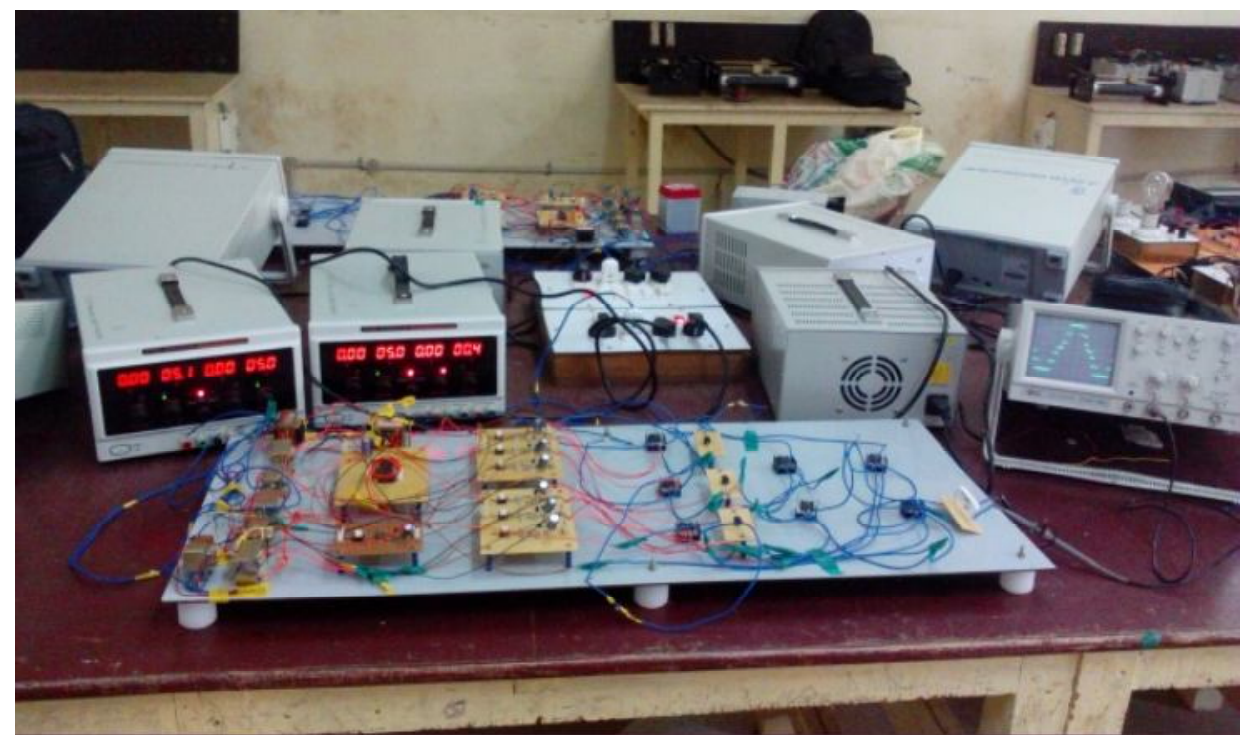

Fig: 13 Hardware Setup for SVPWM based seven level inverter

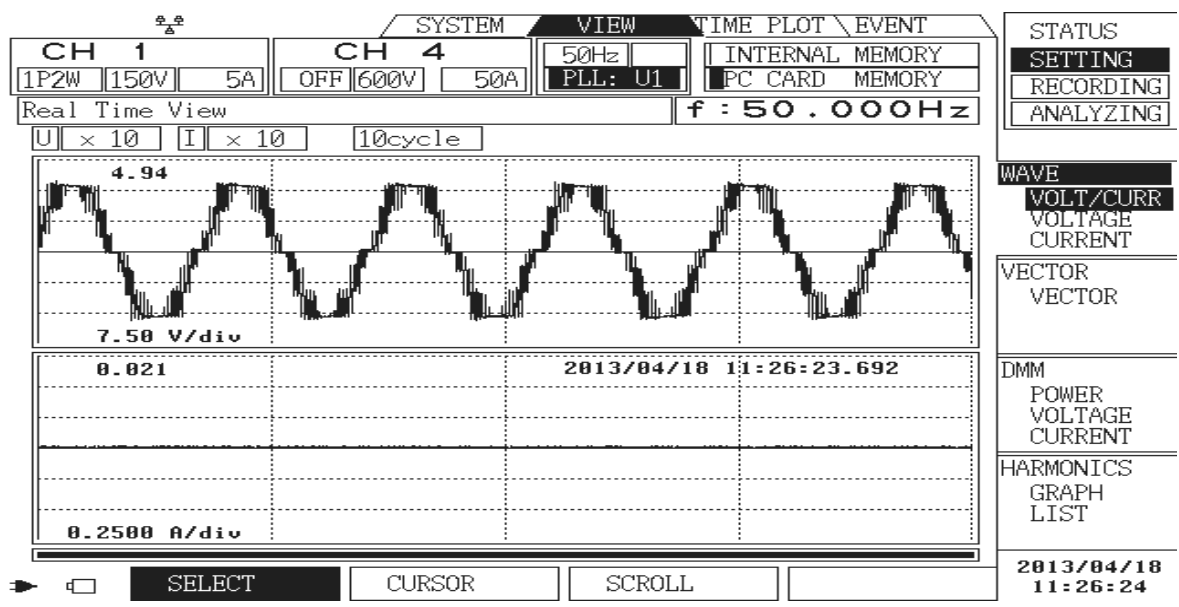

Fig: 14 Seven level output waveform of SVPWM by using Power Quality Analyzer

\begin{tabular}{|c|c|c|c|c|c|c|c|c|c|}
\hline & 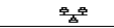 & & \multicolumn{2}{|r|}{ SYSTEM } & \multicolumn{4}{|c|}{ PLOT $\backslash$ EVENT } & \multirow{3}{*}{$\begin{array}{l}\text { STATUS } \\
\text { SETTING }\end{array}$} \\
\hline CH & 1 & & हH & 4 & $50 \mathrm{~Hz}$ & \multicolumn{3}{|c|}{ INTERNAL MEMORY } & \\
\hline 1P2W & 15 av & $5 \mathrm{~A}, \mathrm{OH}$ & 600 & $50 \mathrm{~A}$ & PLL: & \multirow{2}{*}{\multicolumn{3}{|c|}{$=50.000 \mathrm{OHz}$}} & \\
\hline \multicolumn{5}{|c|}{ Real Time View } & & & & & ANALYZING \\
\hline \multicolumn{2}{|c|}{$\mathrm{CH} 1$} & \multicolumn{3}{|c|}{ VALUE iHarmON } & & & & & \\
\hline 1: & 188_-8B & 15.96 & 2: & 2.97 & 7.28 & THD & 17.84 & 42.87 & \multirow{3}{*}{\begin{tabular}{|l} 
WAVE \\
VOLT/CURR \\
VOLTAGE \\
CURRENT \\
\end{tabular}} \\
\hline 3: & 3-68 & $18-42$ & 19: & 1 - 10 & $4-49$ & 35: & 8.59 & 3.84 & \\
\hline $4:$ & $4-86$ & $4-82$ & $20:$ & 0.47 & $\begin{array}{l}1-42 \\
4-27\end{array}$ & $36:$ & $\begin{array}{l}0 \\
0-21 \\
0\end{array}$ & $\begin{array}{l}0.79 \\
0-77\end{array}$ & \\
\hline $6:$ & 2.85 & 2.46 & $22:$ & B- 28 & B.61 & $38:$ & D. 75 & 1 - B1 & \multirow{4}{*}{$\begin{array}{l}\text { VECTOR } \\
\text { VECTOR }\end{array}$} \\
\hline 7: & e.67 & $18-55$ & 23: & - 87 & $1-55$ & 39: & e- 58 & $2-03$ & \\
\hline 8: & $\mathbf{8}-94$ & $\mathbf{1}-\mathbf{e 8}$ & 24: & $5-49$ & $1-23$ & 40: & $\mathbf{1}-\mathbf{8 0}$ & B 89 & \\
\hline 9: & $1-18$ & B.92 & $25:$ & B- $7 \mathbf{B}$ & $1-24$ & 41: & B. 48 & $1-17$ & \\
\hline 10: & e- 53 & - -94 & 26: & - -76 & $2-41$ & 42: & a - $\mathbf{3 0}$ & 1 - & \multirow{4}{*}{$\begin{array}{l}\text { DMM } \\
\text { POWER } \\
\text { VOLTAGE } \\
\text { CURRENT } \\
\end{array}$} \\
\hline 11: & $\begin{array}{l}0-66 \\
0-94\end{array}$ & $1-32$ & 27: & - -66 & - 99 & 43: & - -32 & $1-19$ & \\
\hline $13:$ & $\begin{array}{l}0.94 \\
0.65\end{array}$ & $\begin{array}{l}6.36 \\
1-36\end{array}$ & 20: & $\begin{array}{l}0.34 \\
0.78\end{array}$ & $1-14$ & 44: & $\begin{array}{l}\theta-34 \\
\theta-27\end{array}$ & $\begin{array}{l}2-61 \\
\mathbf{8}-81\end{array}$ & \\
\hline 14: & B. 91 & 4.65 & $30:$ & 0.97 & - -88 & 46: & b. 39 & $1-37$ & \\
\hline 15: & 9.99 & a. 51 & 31: & $2-37$ & B.84 & 47: & B. 88 & B. 71 & \multirow{4}{*}{$\begin{array}{l}\text { HARMONICS } \\
\text { GRAPH } \\
\text { LIST }\end{array}$} \\
\hline $16:$ & B. 57 & 1.37 & 32: & B. 62 & 1 - 19 & $48:$ & B. 36 & B. 65 & \\
\hline 17: & $1-14$ & $1-15$ & 33: & $1-87$ & $1-58$ & 49: & B. 29 & $1-13$ & \\
\hline 18: & $1-14$ & B. 68 & 34: & 0. 51 & 1 - 86 & 50 & B - 28 & $1-32$ & \\
\hline 5 & & & & & & & & & $\begin{array}{l}2013 / 84 / 18 \\
11=33=25\end{array}$ \\
\hline
\end{tabular}

Fig: 15 THD measured by using Power Quality Analyzer 


\section{VII .CONCLUSION}

This paper analyzed the PWM technique for 7 level inverter with two different PWM signals (sine and space vector). The value of THD during hardware implementation is slightly higher than that of simulation results due to the switching losses. The THD has been reduced by this control technique and without filter the output is obtained which is similar to sinusoidal waveform. The cost and switching losses are reduced by the modified cascaded multilevel inverter.

Table 3 Comparison between SVPWM and MSPWM

\begin{tabular}{|l|l|l|}
\hline \multirow{2}{*}{$\begin{array}{l}\text { Modulation } \\
\text { Techniques }\end{array}$} & \multicolumn{2}{|l|}{$\begin{array}{l}\text { Total Harmonic Distortion } \\
\text { Analysis }\end{array}$} \\
\cline { 2 - 3 } & Simulation & Hardware \\
\hline SVPWM & $11.43 \%$ & $17.04 \%$ \\
\hline MSPWM & $18.63 \%$ & $25.06 \%$ \\
\hline
\end{tabular}

Among the two modulation strategies, the THD of SVPWM technique is lower than MSPWM technique as shown in table 3.

\section{ACKNOWLEDGEMENT}

The authors would like to thank the management of Kings College of Engineering, Punalkulam, Thanjavur for supporting to do the research work and publish it.

\section{REFERENCES}

[1] Felipe B. Grigoletto, Márcio Stefanello, Guilherme S. da Silva "Space vector pulse width modulation for Modular Multilevel Converters" IEEE, International Conference On Industrial Electronics Society (IECON 2016) Oct. 23-26, 2016.

[2] P.Jamuna, C.Christober Asir Rajan "MSPWM \& MTPWM Techniques for Asymmetric H-Bridge Multilevel Inverter" IEEE, International Conference On Advances In Engineering, Science And Management (ICAESM -2012) March 30, 31, 2012

[3] Mariusz Malinowski, Senior Member, IEEE, K. Gopakumar, Senior Member, IEEE, Jose Rodriguez, Senior Member, IEEE, and Marcelo A. Pérez, Member, IEEE. A Survey on Cascaded Multilevel Inverters -IEEE Transactions on Industrial Electronics, VOL. 57, NO. 7, July 2010.

[4] Zhong Du1, Leon M. Tolbert2,3, John N. Chiasson2, and Burak Özpineci3. A Cascade Multilevel Inverter Using a Single DC Source.

[5] D. Holmes, and T. Lipo, Pulse Width Modulation for Power Converters Principles and Practice, 2003.

[6] N. A. Rahim and J. Selvaraj, "Multi string five-level inverter with novel PWM control scheme for PV application," IEEE Trans. Power Electron., vol. 57, no. 6, pp. 2111-2123, Jun. 2010.

[7] G.Narayanan, Harish K. Krishnamoorthy, Rajapandian Ayyanar and V.T.Ranganathan, "Space vector Based Hybrid PWM technique for Reduced Current Ripple,” IEEE Trans. Industrial Electron. Vol. 55, no. 4, April 2008.

[8] P. Narasimman, E.Latha Mercy "Design and Comparison of Controller for the Reduction of Conducted Electromagnetic Interference in an Inverter" in Emerging Technology Trends in Circuits and Systems of Circuits and System. ISSN: 2153-1293, Vol. 7, No.7 P.NO:11671176. (2016). 